\title{
Returns Reverse Logistics Management Strategy in E-commerce B2C Market
}

\author{
Wang Qingjun \\ School of Economic and Management \\ Shengyang Aerospace University \\ Shengyang China \\ 32582669@qq.com
}

\author{
Li Yaofei \\ School of Economic and Management \\ Shengyang Aerospace University \\ Shengyang China \\ 362836435@qq.com
}

\begin{abstract}
E-commerce or nothing in 21st century. Nowadays, E-commerce has penetrated into every managerial field. Yet the reverse logistics has already been a great barrier for the further development of $E$ commerce .However, opportunities abound in the Reverse logistics market as well.To beginning with, this paper introduced the features of reverse logistics in the $E$ commerce, discussed the significance that enterprises implement returning reverse logistics, then the three modes of reverse logistics. Next, the management strategy of the process in returning reverse logistics under B2C market were brought out. Further more, the barriers in the implement process were analyzed and some means were provided as well. Finally, at the end of this paper, shows up an example of returning reverse logistics. We can understand the theory better, with the help of the example. Establish an effective system of reverse logistic used for returning management will be the trend, in the 21 st century. The capability of the logistics system will drive the enterprises to grow stronger.
\end{abstract}

Keywords-Returning management ; E-commerce ; Reverse logistics; Strategy

\section{INTRODUCTION}

In recent years, we have seen the overwhelming development of e-commerce. There are more and more companies having transactions with consumers through the e-commerce platform. This business model allows companies to reduce the cost of sales and meet customers' requirements in a timely manner, and the consumers can shop around while staying at home through the Internet and select and purchase products more quickly and easily.

These advantages of e-commerce make both the business managers and consumers very optimistic about the prospects for the development of e-commerce. However, in the transactions of $\mathrm{B} 2 \mathrm{C}$ e-commerce, the phenomenon of returns tends to be bound to exist and gradually it has attracted more and more attention of the business owners. Correct returns logistics management has many advantages, such as lowering logistics costs and improving competitiveness. In e-commerce, it is common that customers return and replace unsatisfactory goods, and e-commerce businesses must reduce the loss caused by returns and recall through effective reverse logistics management, maintain their core competitiveness and enhance corporate reputation. Trading through an online platform, customers and businesses can save a lot of time and space and greatly improve transaction efficiency. This form of Internet e-commerce is mainly the online retail business carried out primarily by means of the Internet. The reverse logistics of e-commerce in this paper mainly refers to the flow process of commodities ordered online returned from the location of the customers to the supply location due to quality or other unsatisfactory factors in online e-commerce, especially the returns logistics in the B2C market.

\section{OVERVIEW}

\section{A. Definition of reverse logistics}

In this paper, the discussion will be focused on the returns and exchange reverse logistics in e-commerce. The returns and exchange reverse logistics also includes the recycling reverse logistics and returns reverse logistics. Recycling reverse logistics means the recycling of the worn-out or defective items originally held by the customers back to the node enterprises in the supply chain, which are then tested, classified and scrapped, or further processed and sold to customers again. However, the process of forward logistics is just the opposite, and returns reverse logistics refers to the situation that the final customers return the products which do not meet the requirements of the original orders directly to the suppliers. (Fig .1) 

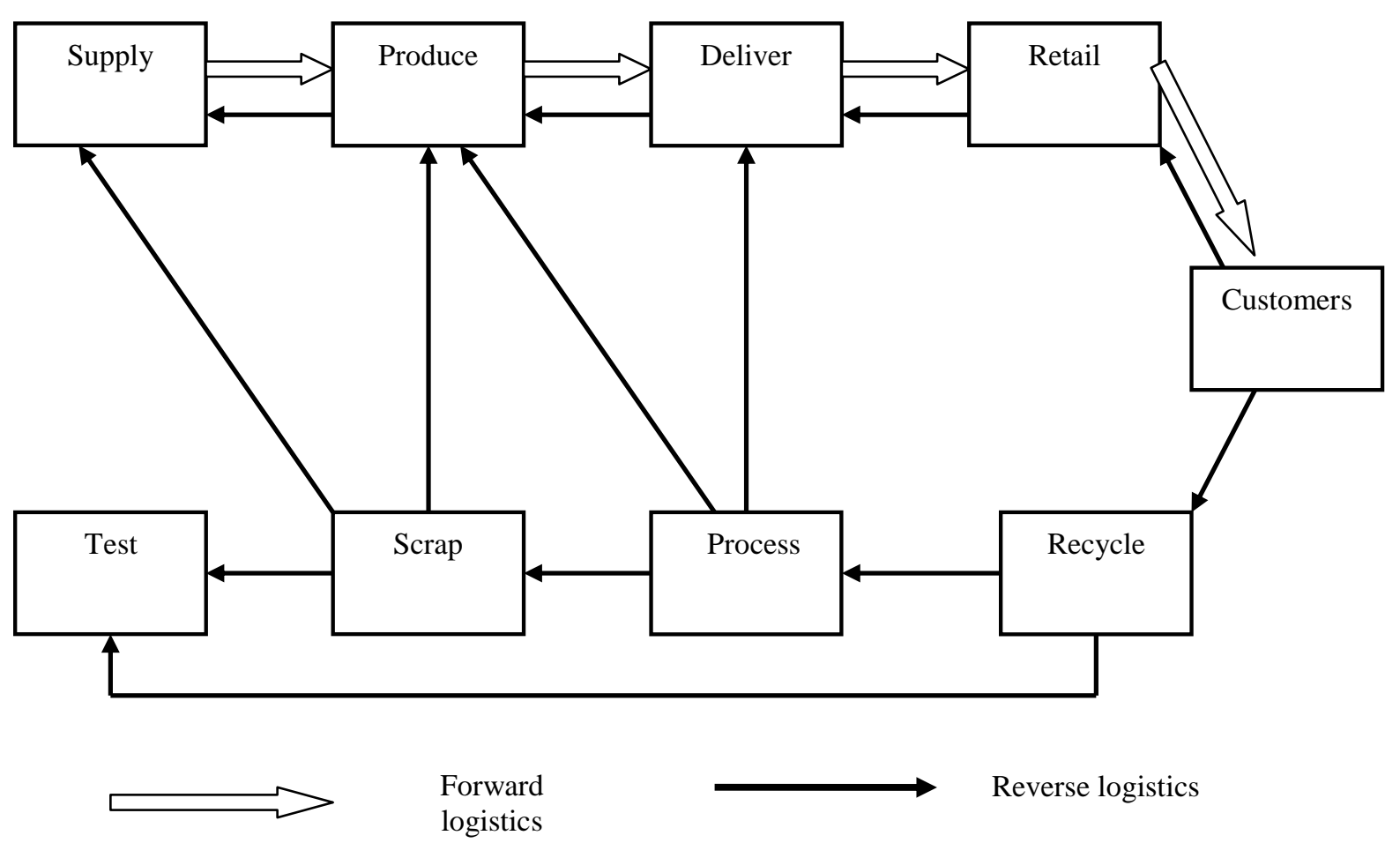

Figure 1. Schematic Reverse Logistics

\section{B. Research on reverse logistics at home and abroad in recent years}

Around the 1990s, countries began to explore and study reverse logistics.

In 1997, the German railway logistics expert Fleischmann divided the research field of reverse logistics into three main research directions: reverse logistics network planning, inventory control and production planning.

In 1999, the American Logistics Management Commission published a survey, the findings of which showed that among the economic aggregate of the USA, the total logistics cost had taken up more than 10 per cent, and about 4 percent of the total logistics cost is generated by the reverse logistics. By remanufacturing and renovating the recycled articles, reverse logistics save a lot of resources and raw materials for the enterprises and brought considerable economic benefits to enterprises.

Although there is no authoritative data statistics on reverse logistics, many domestic enterprises have begun to try and explore in the field of reverse logistics. However, generally speaking, the research on reverse logistics in China is still only at the beginning stage. The reverse logistics field has not yet attracted great attention of domestic enterprises, and most of enterprises, especially those small and medium size ones, do not understand reverse logistics. Meanwhile, the study of third-party logistics industry is started late in China. Many systems are not mature and there are only a few successfully developed third-party reverse logistics service projects at present. In fact, the domestic research still focuses mainly on the theoretical study of reverse logistics, and there are relatively few studies on the practical reverse logistics support systems.

\section{THE REVERSE LOGISTICS IN B2C MARKET}

Currently, the e-commerce model is mainly divided into seven categories of B2B, B2C, C2C, B2M, M2C, B2A and $\mathrm{C} 2 \mathrm{~A}$, and $\mathrm{B} 2 \mathrm{C}$ is the model in e-commerce most widely used by consumers. Under the B2C model, consumers can shop satisfactory goods and quickly learn about the latest product information and special offers at home, and sellers can promote their products with less cost and learn about customers' demand on the Internet. We can say that e-commerce has brought great convenience to both buyers and sellers. However, no gold is pure and no one is perfect. No matter how good something is, it will always have flaws. Because in B2C transactions, consumers make purchasing decisions based entirely on the graphic and text information issued online by the sellers, it often happens that the goods received can not meet the original purchasing wishes of the consumers, which will consequently increase the returns and exchange rate.

The characteristics of $\mathrm{B} 2 \mathrm{C}$ market result in that consumers are likely to give up shopping online simply because of the imperfect mechanism of returns. Reverse logistics is really important for e-commerce, so companies have to regard the reverse logistics as an important strategy for them to reduce operating cost, improve customer satisfaction and enhance core competitiveness. 


\section{THE BARRIERS TO THE IMPLEMENTATION OF RETURNS REVERSE LOGISTICS MANAGEMENT AND IMPROVEMENT STRATEGIES}

\section{A. The existing reverse logistics management strategies}

\section{1) Starting point management}

Just as the idioms go, "take away the firewood under the cooking pot and then the boiling will be stopped". The so-called starting point here just means controlling the returns at the root: First, to ensure transparency of information, it requires the customers to be fully aware of the return policies of the sellers before purchasing, and the sellers to provide customers with complete and correct product information. Second, to protect the interests of consumers, it can be realized through the development of a number of related policies, such as: extending the duration of consumers to cancel the orders in order to reduce to some extent the phenomena that the consumers purchase impulsively and want to return the products when they calm down and feel unsatisfied. Third, while meeting the customers' demands, the sellers have to reduce loss as far as possible. Some appropriate returns restrictions can be developed to put an end to the phenomena of returns without defects and malicious returns.

\section{2) Process Management}

In the process management of reverse logistics, the most important job is to optimize the handling process of the returns, so as to achieve the goals of shortening returns handling cycles, increasing the rate of reselling and improving operational efficiency. In short, it is to improve the standardization and automation of the entire process of returns handling.

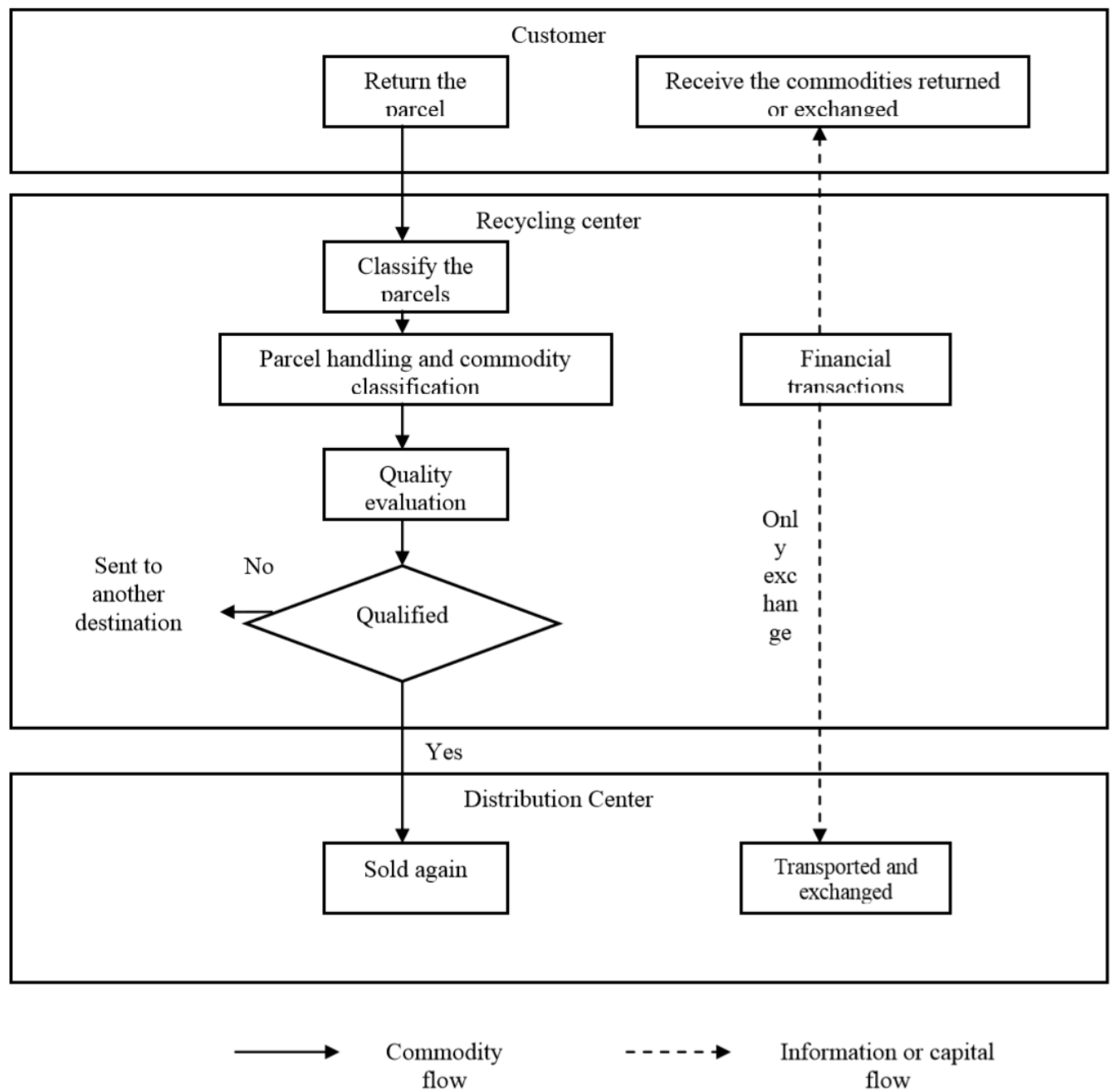

Figure 2. Traditional returns process in e-commerce environment 


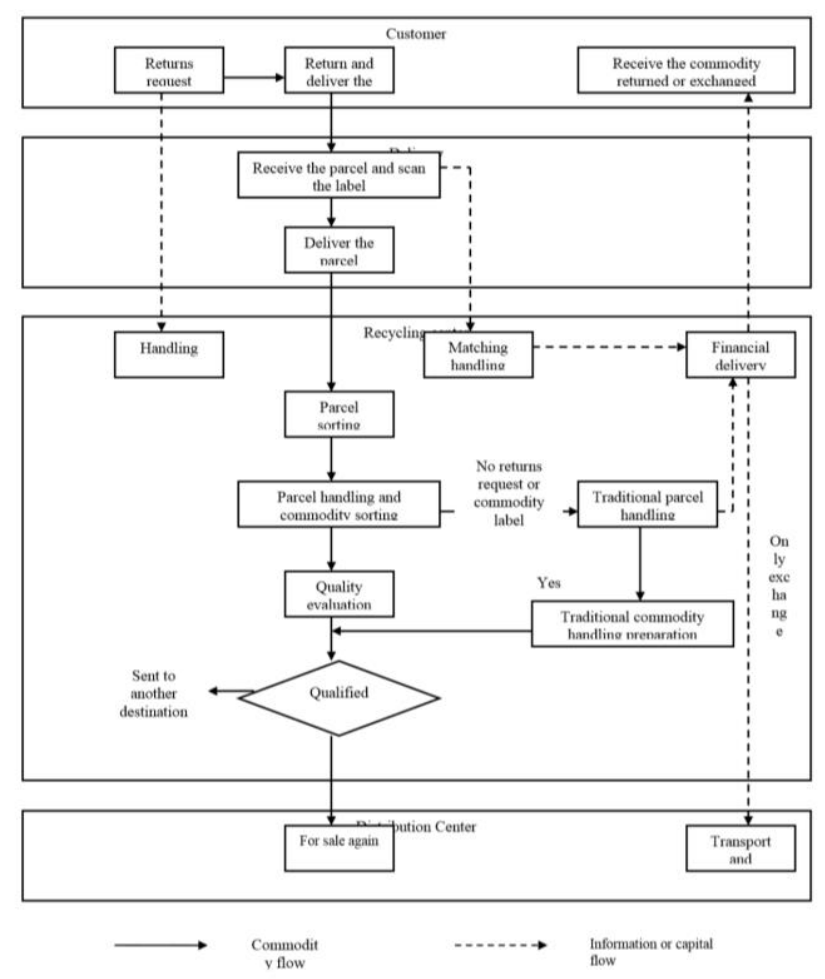

Figure 3. Diagram of electronic returns in e- commerce environment

\section{3) Follow-up management}

The successful handling of a return is not the end of returns management. The idea of sustainable development should be integrated into returns management. It is because the implementation of returns management shall not only aim to successfully handle a return, but to find ways to avoid the reoccurrence of similar returns phenomena. Therefore, it is quite necessary to create a detailed record of returns management and to carry out statistical analysis of these returns data. Every time when returns happen afterwards, immediate horizontal and vertical comparisons are carried out on the returns data. The horizontal comparison is made with the traditional sales channels, while the vertical comparison is to make analysis through comparison with the historical records, so as to discover law and problems, predict the peak of returns effectively and make reasonable arrangement of personnel for handling returns and commodity stocks.

\section{B. Obstacles to implementation}

In order to implement the scientific development concept and promote recycling economy, the government of China has enacted a series of laws, regulations and the liability system, and the development of reverse logistics has begun to take shape. In spite of a lot of excellent management ideas presented before, there are still many obstacles to the practical operation of reverse logistics management.

\section{1) External obstacles}

In accordance with the current situation, the development of reverse logistics industry is still in an infancy stage, during which neither enterprises nor the country can build a complete reverse logistics information processing system. The reverse logistics information system plays an important role in the collection of useful information and the management of the reverse logistics products, as well as in feeding back information to enterprises, providing better customer service and promoting the development of enterprises. Therefore, without this hardware, the supply and demand information between the upstream and downstream units in the supply chain will be not true to the original due to the "bullwhip effect", resulting in greater risks level by level.

The company's profit and environmental protection are in conflict. As the relevant laws and policies are not perfect, in order to meet environmental benchmarks prescribed by the government, many enterprises have to recycle products in large quantities, in order to reduce the adverse impact of some of their products on the environment. However, not all the recycling and processing of products can bring positive effects to enterprises; some even became greater burdens.

2) Internal obstacles

In fact, the biggest obstacle to the implementation of reverse logistics is not the technical problems but attitude, for attitude is everything. If people do not attach importance to the research and development of reverse logistics, it will be difficult to set up a perfect reverse logistics management system. However, there is still a long way to go to make people really pay attention to that and get down to building a complete system. At present, the main obstacles are:

Reverse logistics is not taken seriously. A complete enterprise has already had its own main business and reverse logistics is not likely to be its core business at the very beginning, so the management team of the 
company will not pay special attention to reverse logistics management.

Lack of relevant experience in handling. General enterprises usually have a complete system for the routine management of logistics activities, so when it comes to a problem of reverse logistics, it will be hard for them to handle it.

Limited human and financial resources. It needs a lot of manpower, material and financial resources to build a complete reverse logistics management system. First, there is a high demand for professional talents, but most of the people working in the logistics industry in China are cheap labor without a high level of education. As they have not received much professional and standardized training, they can not master the advanced information processing technology and are not quite aware of the operation mode of reverse logistics.

\section{Improvement Strategies}

1) Improve the degree of emphasis and the business process

It is because of more and more intense competition that the reverse logistics management becomes more and more important. Every enterprise that makes profit thinks about two questions all the time: how to minimize the operating cost and how to increase profits as much as possible? In fact, there is a great opportunity hidden in the reverse logistics, and only those who can seize this opportunity can become leaders in the trend of ecommerce. Customers for enterprises is like water for fish. To make profit, the enterprises not only have to minimize cost, but also have to win the hearts of customers. Therefore, the optimization of return reverse logistics will be a stepping stone for enterprises to achieve success. Attitude is everything. When attention is paid, investment will be put and gains will be possible. Know your rival and know yourself. Find out what mindset causes the customers to return commodities and then adjust the returns policies and further improve the reverse logistics management system, so as to establish a set of standardized automatic business processes. In this way, the amount of returns and the cost of returns can be reduced, and the profit can be increased.

2) Establish reverse logistics information management system

E-commerce operators who want to have a place in the extremely fierce market competition must establish a set of comprehensive reverse logistics tracking system fit for the domestic market environment, so as to timely handle returns requests of customers. The primary condition for the establishment of a reverse logistics information tracking system is to understand the reasons for returns. Generally speaking, the reasons for customers to request returns mainly lie in the following aspects: quality problems, missing parts, missing parts in transit, products expired and out of size and the mistyping of commodity names or numbers and so on. Suit the remedy the case, learn about the reasons for the returns of consumers and then test the products returned by using the information system and make decisions, such as whether they might be sold again or whether some of the components may be for sale again. If it is impossible to sell them again, the commodities should be scrapped or recycled and returned to the manufacturers.

\section{3) Seek strategic alliance partners}

Previously we have discussed the reverse logistics model most suitable for the $\mathrm{B} 2 \mathrm{C}$ market, that is, the third-party reverse logistics model. Although there is some risk, after proper treatment it can be avoided to some extent. At present, domestic enterprises are still in the infancy stage in the field of reverse logistics. If they can form industry alliances, to cooperate with each other, discuss problems encountered in reverse logistics and collaborate to find solutions for common interests, the enterprises will go more smoothly on the road to explore reverse logistics. In today's competitive market, the "win-win" or "multi-win" state is emphasized, so it will surely remove many obstacles to the implementation of reverse logistics to actively seek strategic partners.

\section{CONCLUSION}

Reverse logistics for e-commerce is just like water for fish. It may be assumed that the e-commerce can not develop without the development of reverse logistics. However, whether the $\mathrm{B} 2 \mathrm{C}$ e-commerce market or modern reverse logistics is still at the beginning stage. However, under the free-market environment of this new era, only by laying emphasis to the reverse logistics management in the e-commerce market can the enterprises enhance their core competitiveness and overall strength. Enterprises can establish a coping system in advance by improving the reverse logistics system, to actively handle the returns. The proper management of reverse logistics is an effective way to reduce operating costs, improve customer satisfaction and enhance the core competitiveness for the enterprises adopting the B2C e-commerce business model. It is quite beneficial not only for the enterprises but also for the overall and long-term business development of the country to improve the whole process of returns logistics service from the perspective of system building and information technology.

\section{REFERENCES}

[1] John J. Coyle, C. John Langley, Brian Gibson, Robert A. Novack, Edward J. Bardi. Supply Chain Management: A Logistics Perspective (8th edition) [M]. South-Western College Pub, March 2008.

[2] Martin Christopher. Logistics \& Supply Chain Management: creating value-adding networks (3rd Edition) [M]. FT Press, February, 2005.

[3] Fu Xiaofan. "B2C E-Commerce Market Reverse Logistics Mode Selection and Management”. Beijing University of Posts and Telecommunications (Social Sciences

[4] Edition), 2006, 8(4): 44-47.

[5] Han Jinglun, Du Peifeng. "On the Causes and Strategic Value of Reverse Logistics". Economic problems, 2004, (2) :35-37.

[6] Xu Liang. "Discussion on the Reverse Logistics Coping Strategies in E-commerce". Marketing Week, 2004, (8) :73-75.

[7] Feng Hui. "Research on Reverse Logistics in E-commerce". Modern Management Science, 2004, (3): 29-32.

[8] Jiang Guoping, Zhang Xiandong. B2C E-commerce Returns Cost Control Analysis [EB / OL]. Http://www.a] 156.com, 2005-05-23.

Chen Yu, Tang Chunyong. Analysis of Effective Management Strategies on Reverse Logistics. Soft Science, 2004, 18 (1): 30 -32. 